\title{
Evaluation of the usefulness of laparoscopy in the diagnosis and treatment of adnexal pathologies in the pediatric population
}

\author{
Aleksandra Raźnikiewicz, Wojciech Korlacki, Andrzej Grabowski \\ Department of Children's Developmental Defects Surgery and Traumatology, Medical University of Silesia in Katowice, Zabrze, Poland \\ Videosurgery Miniinv 2020; 15 (2): 366-376 \\ DOI: https://doi.org/10.5114/wiitm.2020.93998
}

\begin{abstract}
Introduction: The current trend in adnexal surgery in children is to minimize the invasiveness of diagnostic and therapeutic procedures, reduce the number of complications and reduce the risk of infertility.

Aim: Evaluation of the usefulness and effectiveness of laparoscopy in diagnostics and treatment of pathological lesions of adnexa in the pediatric population and evaluation of the correlation of imaging with the intraoperative diagnosis during laparoscopy.

Material and methods: The study included 89 patients aged 0-18 years (mean: 12.62) who underwent an emergency or elective laparoscopic procedure due to the suspicion of adnexa pathology in the imaging tests or in which intraoperative pathology of the adnexa was found without previous suspicion of these changes in the imaging tests. Patients were divided into 2 groups according to the procedure (emergency or elective) and into 4 age groups.

Results: The most frequent postoperative diagnosis was an adnexal cyst and ovarian tumor. The ratio of malignant to benign lesions was 0.087. In 32.58\% of patients appendix pathology was found. Coexistence of adnexa and appendix pathology was statistically significantly more frequent in patients undergoing emergency surgery $(p=0.013)$. There was no correlation between the size of the tumor or ovarian cyst and the occurrence of adnexal torsion, and no correlation between the size of the tumor and the degree of torsion of the adnexa. Three conversions were performed. The average operation time was $63.7 \mathrm{~min}$.

Conclusions: Laparoscopic diagnosis and treatment of adnexal pathology seems to be safe due to the low percentage of perioperative complications. It shows high sensitivity in recognizing adnexal pathologies and other defects.
\end{abstract}

Key words: ovarian tumor, ovarian cyst, torsion of the ovary, pediatric gynecology, laparoscopy.

\section{Introduction}

The development of minimally invasive techniques has made them widely used in every field of surgery both as a diagnostic and therapeutic method. These procedures can be safely performed in elective and emergency situations. Laparoscopic diagnostic and diagnostic-therapeutic procedures in the field of adnexal pathologies in women are considered to be the standard in the treatment of benign ovarian lesions. An important advantage of laparoscopy for this group of patients is related to the lower risk of postoperative adhesions, which translates into lower risk of infertility [1-3].

In pediatric surgical gynecology, the most important aspects include correct diagnosis and treatment of cysts and ovarian tumors, correction of congenital genital defects, diagnosis and treatment of endometriosis and treatment of ovarian torsion and/or fallopian tube [4]. Despite the availability of increasingly precise imaging methods (ultrasound, CT, MRI), in some cases laparoscopy is an excellent diagnostic

\section{Address for correspondence}

Aleksandra Raźnikiewicz MD, Department of Children's Developmental Defects Surgery and Traumatology, Medical University of Silesia,

13-15 3 Maja St, 41-800 Zabrze, Poland, phone: +48 792797 870, e-mail: aleraznik@gmail.com 
tool. Moreover, it allows the diagnostic and therapeutic procedures to be carried out during the same surgical intervention [5].

The diagnosis of ovarian and fallopian tube pathologies in children is difficult and often delayed due to the occurrence of non-specific clinical symptoms characterized mainly by broadly defined $a b$ dominal pain. In pediatric gynecology, pain is most often observed in the area of the abdomen or pelvis, which is common on the one hand and very ambiguous on the other. It may be caused by torsion of the adnexa, cysts or tumors in the ovaries, pelvic inflammation syndrome, congenital defects, juvenile pregnancy, ectopic pregnancy, or endometriosis, and may indicate appendicitis or other gastrointestinal, endocrine or urological pathologies [6, 7].

\section{Aim}

The aim of this study is to evaluate the usefulness and effectiveness of laparoscopy in the diagnosis and treatment of adnexal pathologies in the pediatric population and to estimate the frequency and type of occurrence of adnexal lesions in girls, as well as to assess the correlation of imaging tests with the diagnosis found intraoperatively during laparoscopy.

\section{Material and methods}

The research method is a retrospective analysis of patients from infants up to 18 years of age operated with the laparoscopic method in the years 2010 2017. The inclusion criterion for the examination was a laparoscopic procedure performed because of a suspected ovarian or fallopian tube pathology demonstrated by imaging and intraoperatively found pathology of the ovary or fallopian tube without prior suspicion of an adnexal pathology in imaging.

The following medical histories were analyzed: history and physical examination forms, results of laboratory, microbiological and histopathological tests, imaging results, laparoscopic procedure protocols and general anaesthesia protocols, medical order cards, postoperative observation cards and records of the clinic.

In the first stage, medical records of patients were analyzed for initial diagnosis as a suspicion of adnexal pathology and surgical books for intraoperative diagnosis showing pathology of the ovary and/ or fallopian tube.
In the second stage, based on the history of diseases in which the preoperative diagnosis occurred, the following data were collected: age, preliminary pre-operative diagnosis, results of interview and physical examination, laboratory results, imaging results, intraoperative and final diagnosis confirmed by histopathological examination, time of surgery, intraoperative and postoperative complications, follow-up of postoperative period, time of hospitalization.

The final analysis was carried out on 89 patients operated on with the laparoscopic method, in emergency or elective mode between 0 and 18 years of age (average age 12.62). All patients were divided into four age groups (Figure 1):

- group I - children under 1 year old,

- group II - children between 2 and 10 years old,

- group III - children between 11 and 14 years old,

- group IV - children between 15 and 18 years old.

Moreover, all patients, regardless of age, were divided into two main groups:

- group A - patients undergoing emergency surgery (37 patients).

- group B - patients with elective surgery (52 patients).

\section{Results}

In the analyzed group of 89 patients the most frequent indications for a laparoscopic procedure were suspected ovarian cyst in ultrasound $(n=33)$ and suspected ovarian tumor $(n=32)$ (Figures 2 and 3 ). The most common subjective symptom in

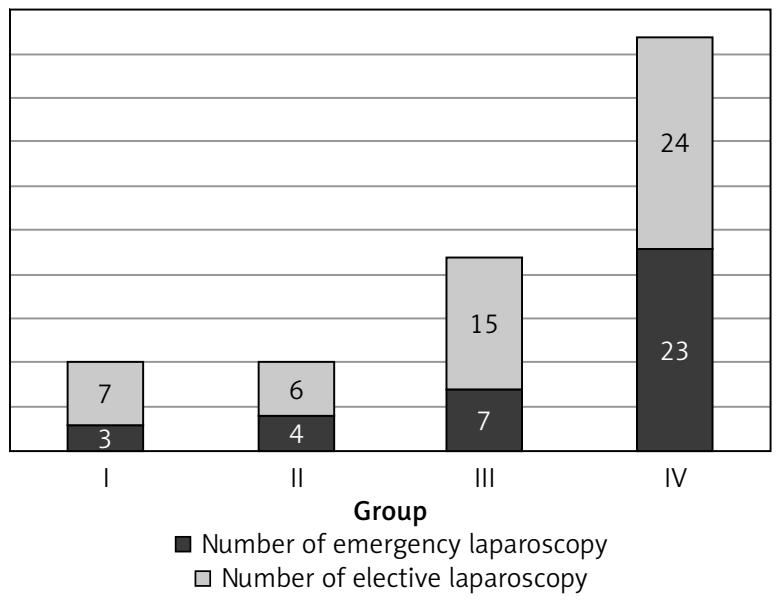

Figure 1. Number of age groups including the number of emergency and elective laparoscopic procedures performed 


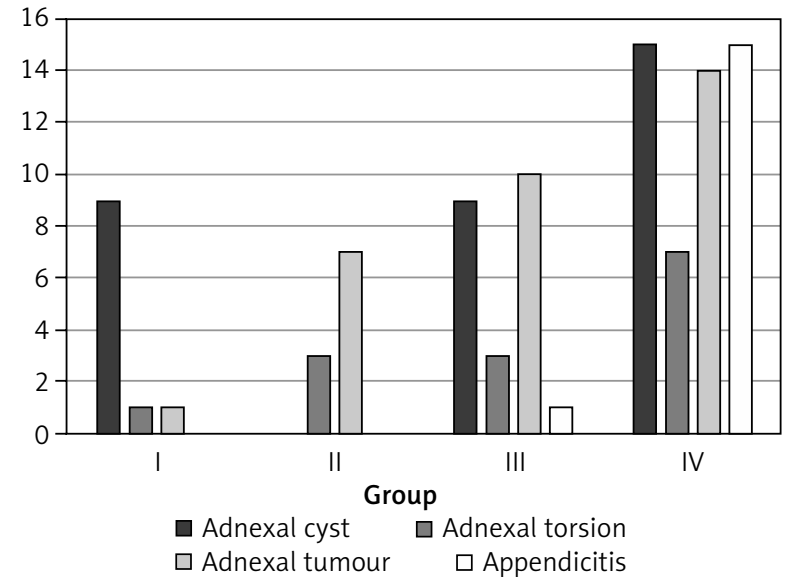

Figure 2. Types and number of indications in each age group
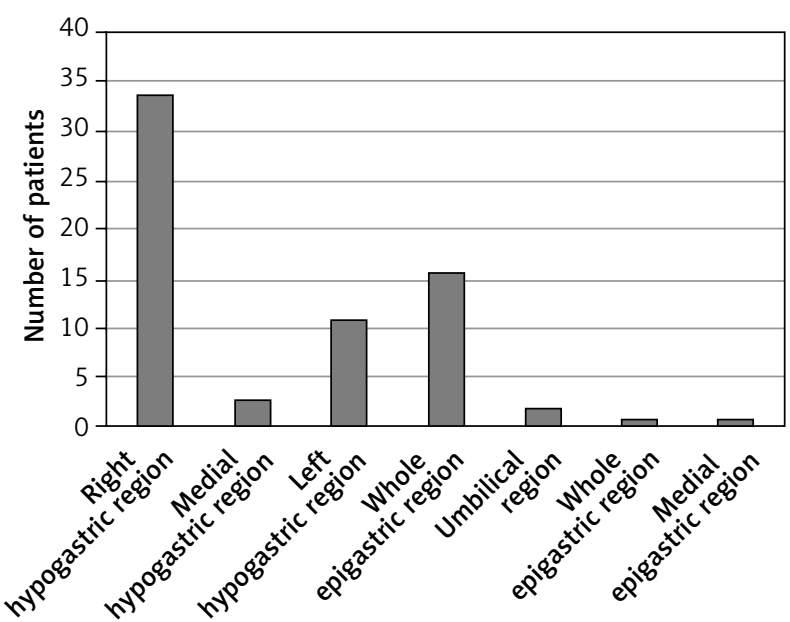

Figure 4. Location of pain in the examined group of patients

the study group was right abdominal pain (Figure 4). Transabdominal ultrasonography was used as the basic diagnostic tool in all 89 patients. Additionally, in 14 patients magnetic resonance imaging (MRI)

Table I. Types of ovarian pathology in patients operated on because of suspected appendicitis

\begin{tabular}{|lcc|}
\hline Type of adnexal pathology & Group III & Group IV \\
\hline Teratoma maturum & 2 \\
\hline Ovarian cyst & 6 \\
\hline Ruptured cyst & 5 \\
\hline Multi-cyst ovary & 2 \\
\hline Periovarian cyst & \\
\hline
\end{tabular}

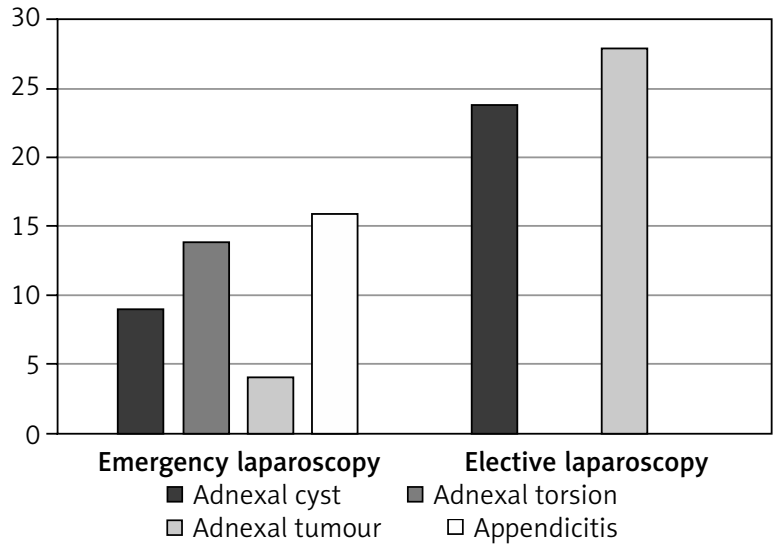

Figure 3. Types and number of indications for emergency and elective laparoscopy

was performed as an extension of the diagnosis and 8 patients were diagnosed with computed tomography. In the case of suspected neoplastic lesion, large size or irregular morphology of cysts, tumor markers including $\beta$-hCG, $\alpha$-fetoprotein, CA125 and lactate dehydrogenase (LDH) were examined.

The most common postoperative diagnosis was an adnexal cyst, i.e. $70.79 \%(n=63)$. The second most frequent pathology of adnexa was ovarian tumor $28.01 \%(n=25)$ with a significant prevalence of benign lesions $(n=23)$. The most numerous group of benign lesions was related to the mature teratoma $(n=20)$. In two cases malignant lesions were found: juvenile granulosa cell tumor and mixed tumor, whose main tissue was sex cord tumors with annular tubules (SCTAT) with separate foci of juvenile granulosa cell tumor. The malignant to benign lesion ratio was $2: 23$ (0.087).

In $32.58 \%$ ( $n=29)$ of operated patients appendix pathology was found. Unsuspected appendix pathology was significantly more frequent in emergency than elective laparoscopy $(p=0.013)$. In patients who underwent emergency laparoscopy because of suspected appendicitis, the most common pathology of adnexa was a cyst $(n=14)$ (Table I). On the other hand, in 13 (14.61\%) patients operated on due to adnexal pathology suspicion, appendix pathology coexisted (Figure 5). In addition to adnexa and appendix pathology, laparoscopy showed the presence of such pathologies as tipped uterus, adhesions, intestinal malrotation and the presence of Ladd's bands.

The total number of diagnoses was higher than the number of patients due to coexistence of ad- 
nexal and appendix pathologies, the occurrence of one or more adnexal pathologies in 1 patient or the occurrence of different pathologies on the right and left side (Tables II and III).

In group I, in $50 \%$ of cases the suspicion of adnexal pathology was raised during the prenatal period during routine ultrasound examination in pregnancy. In 3 cases intrauterine torsion of the adnexa was found. Due to macroscopic features of ovarian and/or fallopian tube necrosis, these structures were resected intraoperatively. In one case, the ovary and fallopian tube were auto-amputated during torsion of the ovary with a cyst. Histopathological examination confirmed benign changes in this group.

Group II revealed the highest percentage of adnexal torsion (70\%). One patient at the age of 10 years had a malignant tumor: sex cord tumor with annular tubules (SCTAT) with separate foci of the juvenile granulosa cell tumor. This patient demonstrated a growing abdominal circumference with mass effect, and in the imaging studies a polycyclic cystic lesion filling the pelvis and abdominal cavity was described. Laboratory tests showed an elevated Ca-125 marker level (101.4 IU/ml). The tumor was resected according to an oncological protocol.

In group III, ovarian cysts dominated in the final diagnosis. In one of the 13-year-old patients a malignant neoplasm of juvenile granulosa type was found, which in computed tomography was described as a cystic tumor structure with a small solid component, probably derived from the right ovary, measuring $85 \times 175 \times 260 \mathrm{~mm}$, reaching the epigastric region and modelling the bladder. In laboratory tests

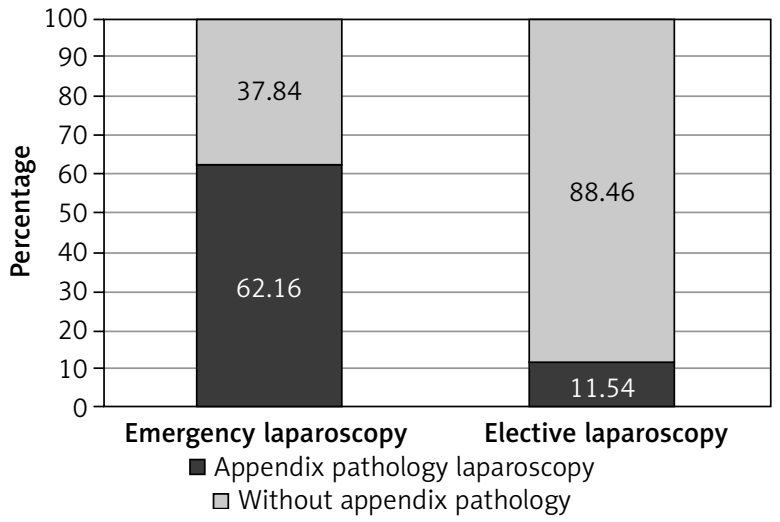

Figure 5. Prevalence of appendix pathology in final diagnosis in elective and emergency laparoscopy $(p=0.013)$

only elevated LDH concentration (200 IU/ml) was observed, without elevation of other cancer markers.

In group IV, the ovarian cyst was most frequently found. In 23 patients, apart from ovarian pathology, appendix pathology was revealed. Twelve benign tumors were diagnosed, including ovarian serous cystadenofibroma $(n=2)$, ovarian seromucinous cystadenoma $(n=1)$ and mature teratoma $(n=9)$.

In 86 patients, surgical procedures were performed on the adnexa (Table IV). The most frequent procedure was cystectomy, which was performed in 49 patients. Cysto-ovariectomy was performed only in group I $(n=5)$ because of the cyst destroying healthy ovarian parenchyma, with no features of ovarian viability. Moreover, 8 scarifications and 2 marsupializations of adnexal cysts were performed. The second

Table II. Number of diagnoses in age groups I-IV and total number of diagnoses in the study group

\begin{tabular}{|c|c|c|c|c|c|}
\hline Final diagnosis & Group I & Group II & Group III & Group IV & Total \\
\hline Ovarian cyst & 9 & 3 & 13 & 28 & 53 \\
\hline Periovarian cyst & 0 & 0 & 2 & 8 & 10 \\
\hline Multi-cyst ovary & 1 & 0 & 2 & 4 & 7 \\
\hline Ruptured cyst & 0 & 0 & 1 & 10 & 11 \\
\hline Adnexal torsion & 6 & 7 & 5 & 1 & 19 \\
\hline Teratoma maturum & 0 & 3 & 8 & 9 & 20 \\
\hline Malignant cancer & 0 & 1 & 1 & 0 & 2 \\
\hline Cystadenofibroma serosum & 0 & 0 & 0 & 2 & 2 \\
\hline Cystadenoma serosum-mucinosum & 0 & 0 & 0 & 1 & 1 \\
\hline Appendix pathology & 0 & 3 & 3 & 23 & 29 \\
\hline
\end{tabular}


Table III. Number of final diagnoses in the group of patients operated on in an emergency and elective procedure

\begin{tabular}{|lcc|}
\hline Final diagnosis & $\begin{array}{c}\text { Emergency } \\
\text { laparoscopy } \\
\text { (Group A) }\end{array}$ & $\begin{array}{c}\text { Elective } \\
\text { laparoscopy } \\
\text { (Group B) }\end{array}$ \\
\hline Ovarian cyst & 30 & 23 \\
\hline Periovarian cyst & 3 & 7 \\
\hline Multi-cyst ovary & 3 & 4 \\
\hline Ruptured cyst & 8 & 3 \\
\hline Adnexal torsion & 10 & 17 \\
\hline Teratoma maturum & 3 & 2 \\
\hline Malignant cancer & 0 & 2 \\
\hline Cystadenofibroma serosum & 0 & 6 \\
\hline $\begin{array}{l}\text { Cystadenoma serosum- } \\
\text { mucinosum }\end{array}$ & 0 & 1 \\
\hline Appendix pathology & 23 & \\
\hline
\end{tabular}

most frequently performed surgical procedure on the adnexa was tumorectomy $(n=15)$ leaving a healthy ovarian parenchyma. Tumoro-ovariectomy $(n=7)$ was performed when the tumor caused complete destruction of the ovarian parenchyma, whereas tumoro-adnexectomy was performed because of the necrotic features of adnexa in the course of their torsion together with the tumor. Moreover, in the case of torsion of the adnexa, 8 torsional derotations, 6 ovarian biopsies in doubtful cases after derotation of the adnexa and 2 adnexectomies were performed due to the characteristics of ovarian and fallopian tube necrosis in the course of a torsion. One resection of the fallopian tube was performed due to the impossibility of separating from the fallopian tube the wall of the giant cyst after draining more than $3000 \mathrm{ml}$ of liquid content from it.

Appendectomy was performed in 33 patients, of whom 29 had a histopathological examination confirming the pathology of the appendix. The average time of the procedure was $63.7 \mathrm{~min}$. No iatrogenic complications or bleeding requiring intervention or blood transfusion were observed during the procedure. The average time of hospitalization was 4.34 days. No intraoperative or perioperative complications were observed. In the study material, out of 89 laparoscopic procedures, 3 conversions were performed: in 2 patients due to significant lesion

Table IV. Types of procedures in groups I-IV

\begin{tabular}{|c|c|c|c|c|}
\hline Laparoscopic procedure & Group I & Group II & Group III & Group IV \\
\hline Cystectomy (cyst resection) & 4 & 1 & 14 & 30 \\
\hline Cysto-ovariectomy & 5 & & & \\
\hline Tumoro-ovariectomy & & 2 & 2 & 3 \\
\hline Tumoro-adnexectomy & & & 2 & \\
\hline Resection of the fallopian tube & & & & 1 \\
\hline Adnexectomy & 1 & 2 & & \\
\hline Tumorectomy & & 2 & 5 & 9 \\
\hline Torsion derotation & 2 & 3 & 2 & 1 \\
\hline Collecting an ovarian specimen & & 2 & & 4 \\
\hline Marsupialization & & & 1 & 1 \\
\hline Scarification & 1 & & 2 & 5 \\
\hline Conversion & 2 & & & 1 \\
\hline Additional incision & & & 1 & \\
\hline Appendectomy & & 4 & 4 & 25 \\
\hline Release of Ladd's bands & & & & 1 \\
\hline Release of adhesions & & & 1 & 4 \\
\hline Lymph nodes collection & & & & 1 \\
\hline
\end{tabular}


size, in 1 due to equipment failure (fiber optic). In 2 cases additional incisions were made to evacuate the lesion of significant size (1 Pfannenstiel incision, 1 widening the incision at the point of introduction of the trocar with optics in the navel area).

Statistical analysis showed no correlation between the size of the tumor or ovarian cyst and torsion of the adnexa. It also showed no correlation between the size of the tumor and the severity of torsion of the ovary and/or fallopian tube. There were no significant statistical differences in cyst size depending on the age group.

In 41 cases of ovarian cysts, abdominal ultrasound examination performed before the procedure correlated with intraoperative and histopathological image. In 20 cases the result was false negative and in 13 cases false positive. Ultrasound sensitivity in terms of ovarian cyst diagnosis was $67.21 \%$ and specificity was $50 \%$.

In 5 cases, ultrasound examination of the abdominal cavity performed before the procedure showed features of adnexa torsion, which were confirmed intraoperatively. In 5 cases, the ultrasound result for adnexa torsion was false positive and in 14 cases false negative. Ultrasound sensitivity to adnexal torsion is $26.32 \%$ and specificity $92.75 \%$.

In 7 cases, the ultrasound examination of the abdominal cavity performed before the procedure showed features of appendicitis, which were confirmed intraoperatively and in histopathological examination. In 22 cases ultrasound did not detect features of appendix pathology - a false negative result. The sensitivity of ultrasound in relation to the diagnosis of appendix pathology is $24.15 \%$, while the specificity is $100 \%$.

\section{Discussion}

Although pathologies of the adnexa in children are rare, they cover a wide spectrum of lesions such as non-cancer ovarian cysts, twisted ovaries and benign and malignant neoplasms [8-10]. These pathologies often require surgical intervention. Laparoscopic procedures in pediatric gynecology, despite their slow acceptance, have now become a gold standard both as a diagnostic and therapeutic tool. They make it possible to limit invasive interventions, i.e. open access, to the necessary minimum.

In the analyzed material, an ovarian cyst was found in $59.55 \%$ of cases. In 49/89 cases cystecto- my and in 5/89 cysto-ovariectomy were performed. In the pediatric population, the frequency of surgical intervention due to ovarian cyst varies between $17.1 \%$ and $43.6 \%$ of all laparoscopic procedures performed due to adnexal pathology [11-13]. This number may be underestimated due to the small amount of papers summarizing the number of laparoscopic procedures performed in pediatric gynecology. Small ovarian cysts are detected occasionally in 2-5\% of children before puberty. The majority of these patients are newborns due to maintaining hormonal stimulation of the placenta or stimulation of maternal hormones [10,11, 14]. Even greater detection of ovarian cysts (30\%) occurs in female fetuses and is in fact disproportionately high given that 1 in 100,000 newborns has an ovarian cyst found. The decrease in the number of diagnoses results from spontaneous cyst involution at birth or from intrauterine ovarian torsion or immediately after birth [14]. Congenital ovarian cysts constituted $5.62 \%$ of our patients.

Laparoscopy is a useful diagnostic tool in cases of unspecified abdominal pain located in the lower abdomen and right iliac fossa, especially in the case of suspected appendicitis with no characteristic symptoms. It should be noted that the torsion of the ovary is more frequent on the right side at a $3: 2$ ratio to the opposite side. This is due to the presence of sigmoid in the left iliac fossa, which limits the mobility of adnexal structures, which reduces the risk of torsion on the left side $[6,15,16]$. The literature also describes cases of synchronous and asynchronous torsion of the adnexa on both sides [17, 18]. Patients with functional ovarian cysts or ruptured cysts may present acute abdominal symptoms, which are consistent with those of acute appendicitis [6]. In the study, $38.2 \%(n=34)$ of pain cases were located in the right lower abdomen and the patients were qualified for surgery due to suspected acute appendicitis. On the other hand, $14.61 \%$ of patients operated on because of suspected adnexal pathology had coexisting adnexal pathology.

The incidence of ovary and/or fallopian tube torsion is estimated at 4.9 per 100,000 girls aged 120 years [19-21]. This represents about 3\% of all cases of children with acute abdominal pain requiring emergency surgery [22].

In our material, torsions of ovaries were found in $21.35 \%(n=19)$ of cases, of which $52.6 \%(n=10)$ underwent an emergency operation. Only 5 patients were diagnosed with torsional traits by ul- 
trasonography, whereas in 14 cases the result was false negative. In 5 other cases the ultrasound result for adnexal torsion was false positive. Although ultrasonography is the method of choice for the imaging of adnexal torsion, unfortunately, it is not a definitive diagnosis [20, 22]. Moreover, up to $60 \%$ of cases of torsion of the ovary are not detected during ultrasonography and the use of the Doppler function is of limited value due to the presence of double vascularization of the ovary, which makes it impossible to explicitly exclude torsion [23-27]. This often leads to delayed diagnosis and longer time from the first symptoms to surgery [28]. Therefore, it seems justified to use laparoscopy as a tool verifying the actual condition, providing unambiguous diagnosis and allowing the majority of procedures to be performed on the ovaries, such as derotation with or without oophoropexy, resection of a tumor or ovarian cyst, and additional procedures such as appendectomy [29].

In most cases, adnexal torsion coexists with an ovarian cyst or tumor (benign or malignant) [30]. There are also described cases of torsion without concurrent pathology occurring with the frequency from $16 \%$ to $67 \%[20,31,32]$. In the analyzed material $21.05 \%(n=4)$ of adnexal torsion occurred without additional ovarian pathology. There are also opinions that in the pediatric group, adnexal torsion without any concurrent pathology is more frequent than in adult women [22, 33-35]. This is caused by a relatively long fallopian tube and a longer mesentery of the ovary and fallopian tube in relation to the uterus or by venous congestion of the adnexa due to hormonal activity. Also, sudden acceleration or slowing down of body movements, strong vomiting and coughing, often occurring in this age group, may lead to increased pressure in the abdominal cavity and cause ovarian torsion [22, 33-35].

In the material studied, adnexal torsions were most commonly found secondary to an ovarian cyst (52.63\%) or mature teratoma (26.32\%), which also in the available literature are reported as the most common causes of adnexal torsion [6]. Adnexal torsions were not observed secondary to malignant ovarian tumors. This results from rarely occurring ovarian malignant lesions in the pediatric population [6]. In addition, malignant lesions are often accompanied by locally limited inflammatory and fibrotic lesions, which results in restrictions on the mobility of surrounding tissues $[20,36]$. Only $0.5 \%$ to $8 \%$ of adnexal torsions are secondary to malignant lesions [19, 37, 38].

Many authors believe that the size of a cyst or tumor is a predictive feature of adnexal torsion [30, 39]. The imaging revealing an enlarged ovary compared to the contralateral ovary or larger in comparison to the age-approved volume standards should arouse the suspicion of torsion [40, 41]. The ovary size greater than $5 \mathrm{~cm}$ has the highest diagnostic sensitivity for torsion [31]. The analysis, contrary to the literature data, did not show any correlation between the size of the tumor or cyst of the ovary and the occurrence of adnexal torsion.

It is considered that cysts larger than $5 \mathrm{~cm}$ not diminishing for a period of 3 months and not undergoing conservative treatment should be eligible for surgery in children. As mentioned above, a persistent large ovarian cyst increases the risk of its torsion, and can also have a destructive effect on the remaining ovarian parenchyma, disrupting its hormonal and reproductive function [5, 42]. The size of the cyst or tumor at present is not a limitation for laparoscopy and there is no clear answer in the literature as to what size of ovarian cyst should be considered a contraindication for laparoscopic surgery [43]. In the pediatric population, operating on giant cysts can, however, be a challenge due to the limited operational field and the risk of cyst rupture [44-46]. Ovarian cysts are traditionally labeled large when they are more than $5 \mathrm{~cm}$, and giant or bulky when they are over $15 \mathrm{~cm}$. In the pediatric population, cyst size is assessed based on its depth in the peritoneal cavity [47]. Some authors define a huge ovarian cyst as reaching the navel, which seems to be well justified in relation to the pediatric population $[48,49]$.

In the analyzed material, the largest cyst had a diameter of $29 \mathrm{~cm}$. In computed tomography it was described as a limited fluid space filling the pelvis and abdominal cavity reaching the level of Th10, displacing the epigastric organs. During the procedure, cyst puncture was performed under the control of laparoscopy; it was resected with sparing of part of the ovarian parenchyma and evacuated from the abdominal cavity by an enlarged incision under the navel. Available reports describe several recognized methods of supplying giant ovarian cysts requiring decompression, which is necessary for laparoscopic resection: transdermal cyst drainage under ultrasound control, cyst decompression by mini- 
laparotomy, and aspiration of cyst contents under laparoscopic control [44, 47, 50-52]. In some cases, evacuation of the cyst, despite decompression, can be difficult. Then removal of the resected cyst is possible by widening the incision of either the trocar access or suprapubic minilaparotomy. According to the literature, incisions not exceeding $5 \mathrm{~cm}$ made to evacuate a tumor or an organ completely excised are not conversions [53].

Giant cysts are usually benign. Before surgery, it is recommended that they be thoroughly diagnosed (diagnostic imaging, tumor markers) to initially exclude malignant lesions [47]. In one case, a $29 \mathrm{~cm}$ cyst turned out to be seromucinous cystadenoma - a very rare benign ovarian tumor, currently classified among serous-mucous tumors according to the WHO classification from 2014 [54]. It was previously included in ovarian mucous cystadenoma tumors, which constituted about $25 \%$ of the most common benign ovarian epithelial neoplasms alongside serous cystadenoma, constituting $75 \%$ of these tumors $[55,56]$. The mucous subtype occurs mainly in middle-aged adult women and is extremely rare in children and adolescents, whereas seromucinous tumor is even rarer $[57,58]$. In the available literature, two cases of seromucinous cystadenoma in the pediatric population have been described [59].

Ovarian tumors in pediatric patients are very rare and constitute only $1 \%$ of all tumors of pediatric age, and only $10 \%$ of them are malignant [6, 60-64]. In the analyzed material, malignant tumors accounted for $8 \%$ of the ovarian tumors. In women, the classical treatment of ovarian tumors involves the resection of the tumor with the ovary. However, due to possible fertility problems, ovary-saving surgery has become very popular [65]. In children operated on due to ovarian pathology, in order to maintain fertility, it is important to resect the tumor with the ovary while saving the ovarian parenchyma, especially bearing in mind the fact that most pathologies are benign lesions. In the material studied, 65 treatments were performed to save the ovarian parenchyma - 16 tumorectomies and 49 cystectomies. On the other hand, ovariectomy and adnexectomy were performed in the absence of visible healthy ovarian parenchyma or because of massive torsion and secondary necrotic lesions. Many authors recommend ovarian saving surgery in all children whose ovarian tumors have not been preoperatively diagnosed as malignant $[66,67]$. In cas- es where the malignant tumor was postoperatively diagnosed, reoperation should be considered [67]. The size of a tumor does not affect the decision to perform the ovarian parenchyma-saving resection. Tumor removal while saving ovarian parenchyma is possible even with large tumors [68]. In the material under study, the largest resected lesion $(29 \mathrm{~cm})$ was benign, so the tumor size is not a sign of its potential malignancy [69]. The most common reason for ovarian resection with a tumor was no clear borderline between the lesion (tumor or cyst) and a healthy ovarian parenchyma. Similar observations can also be found in the reports of other authors [65]. In turn, Williamson et al. stated that the size of a teratoma during the resection is important. Their experience shows that it is easier to find the border between the ovary and the teratoma when the tumor is less than $8 \mathrm{~cm}$. Due to the favorable prognosis of benign ovarian tumors, low relapse rate (0-4\%), low risk of ovarian torsion in the future, and preservation of fertility and gonadal function, performing ovarian parenchyma-saving surgery seems to be an important aspect of surgical treatment of ovarian tumors in the pediatric population $[36,70]$. Another factor in favor of laparoscopy is a lower risk of postoperative adhesions forming in the pelvis, which may be one of the causes of infertility [71]. Laparoscopic procedures have been demonstrated to cause fewer postoperative adhesions compared to open methods [1, 72, 73].

Due to the limited availability of gynecologists specializing in pediatric gynecology, the obligation of adnexal pathology surgery remains with pediatric surgeons. During laparoscopic surgery in young girls, first of all in pre-pubertal girls, the most important factor is awareness of the anatomical differences in the pelvic organs between young and adult women. First in children, the fallopian tube is relatively long, the uterus is smaller, and the position of the ovary is higher, which is the result of the underdeveloped connective tissue surrounding the ovary, which should support it [74]. Lower abdominal volume and flaccid abdominal wall are factors that increase the risk of laparoscopic procedures. The abdominal wall around the navel is thinner and the abdominal aorta is located directly below it; therefore damage to a large blood vessel is more likely in children when introducing the first trocar [75]. In addition, the upper margin of the bladder is in a higher position than in women, which carries a greater risk of blad- 
der damage during insertion of the suprapubic port [2]. Close cooperation of the pediatric surgeon with the gynecologist and joint care of pediatric patients seem to be very important [76]. This model of care is also used in our center. There were no intraoperative complications in the analyzed material.

\section{Conclusions}

Laparoscopic diagnosis and treatment of adnexal pathology appears to be safe due to the low percentage of perioperative complications and high sensitivity in the diagnosis of not only the pathology of the ovary and fallopian tube, but also other abdominal and pelvic defects or diseases. However, the surgical treatment of adnexal pathologies in the pediatric population requires a unique and cautious approach with particular regard to maintaining gonadal function and fertility, as well as anatomical differences and physiological conditions of the pelvic organs of girls of different ages.

\section{Conflict of interest}

The authors declare no conflict of interest.

\section{References}

1. Anderson SA, Beierle EA, Chen MK. Role of laparoscopy in the prevention and in the treatment of adhesions. Semin Pediatr Surg 2014; 23: 353-6.

2. Dural O, Yasa C, Bastu E, et al. Laparoscopic outcomes of adnex al surgery in older children and adolescents. J Pediatr Adolesc Gynecol 2017; 30: 128-31.

3. Kim HB, Cho HY, Park SH, Park ST. Laparoscopic ovarian surgery in children and adolescents. JSLS 2015; 19: e2014.00253.

4. Sajdak S, Moszyński R. Role of endoscopic techniques in pediatric and adolescent gynecology. Nowa Medycyna 2004; 1.

5. Rieger MM, Santos XM, Sangi-Haghpeykar H, et al. laparoscopic outcomes for pelvic pathology in children and adolescents among patients presenting to the pediatric and adolescent gynecology service. J Pediatr Adolesc Gynecol 2015; 28: 157-62.

6. Cass DL, Hawkins E, Brandt ML, et al. Surgery for ovarian masses in infants, children, and adolescents: 102 consecutive patients treated in a 15-year period. J Pediatr Surg 2001; 36 693-9.

7. Eskander RN, Bristow RE. Adnexal masses in pediatric and adolescent females: a review of the literature. Curr Obstet Gynecol Rep 2012; 1: 25-32.

8. Pienkowski C, Tauber MT, Beladj N, et al. How to manage a symptomatic ovarian follicular cyst in a female child? Arch Pediatr 1994; 1: 903-907.

9. Schultz KA, Ness KK, Nagarajan R, Steiner ME. Adnexal mass es in infancy and childhood. Clin Obstet Gynecol 2006; 49: 464-79.
10. Freud E, Golinsky D, Steinberg RM, et al. Ovarian masses in children. Clin Pediatr 1999; 38: 573-7.

11. Shimada T, Miura K, Gotoh H, et al. Management of prenatal ovarian cysts. Early Hum Dev 2008; 84: 417-20.

12. Balan P. Ultrasonography, computed tomography and magnetic resonance imaging in the assessment of pelvic pathology. Eur J Radiol 2006; 58: 147-55.

13. De Silva KS, Kanumakala S, Grover SR, et al. Ovarian lesions in children and adolescents - an 11-year review. J Pediatr Endocrinol Metab 2004; 17: 951-7.

14. Bagolan P, Giorlandino C, Nahom A, et al. The management of fetal ovarian cysts. J Pediatr Surg 2002; 37: 25-30.

15. Germain M, Rarick T, Robins E. Management of intermittent ovarian torsion by laparoscopic oophoropexy. Obstet Gynecol 1996; 88: 715-7.

16. Göçmen A, Karaca M, Sari A, et al. Conservative laparoscopic approach to adnexal torsion. Arch Gynecol Obstet 2008; 277: 535-8.

17. Beaunoyer M, Chapdelaine J, Bouchard S, Ouimet A. Asynchronous bilateral ovarian torsion. J Pediatr Surg 2004; 39: 746-9.

18. Dumont T, Caccia N, Allen L. Pediatric synchronous bilateral ovarian torsion: a case report and review of the literature. J Pediatr Surg 2011; 46: e19-23.

19. Guthrie BD, Adler MD, Powell EC. Incidence and trends of pediatric ovarian torsion hospitalizations in the United States, 2000-2006. Pediatrics 2010; 125: 532-8.

20. Kokoska ER, Keller MS, Weber TR. Acute ovarian torsion in children. Am J Surg 2000; 180: 462-5.

21. Celik A, Ergun O, Aldemir $\mathrm{H}$, et al. Long-term results of conservative management of adnexal torsion in children. J Pediatr Surg 2005; 40: 704-8.

22. Breech LL, Hillard PJ. Adnexal torsion in pediatric and adolescent girls. Curr Opin Obstet Gynecol 2005; 17: 483-9.

23. Meyer J, Harmon C, Harty MP, et al. Ovarian torsion: clinical and imaging presentation in children. J Pediatr Surg 1995; 30: 1433-6.

24. Servaes S, Zurakowski D, Laufer MR, et al. Sonographic findings of ovarian torsion in children. Pediatr Radiol 2007; 37: 446-51.

25. Stark JE, Siegel MJ. Ovarian torsion in prepubertal and pubertal girls: sonographic findings. AJR Am J Roentgenol 1994; 163 : 1479-82.

26. Sasaki KJ, Miller CE. Adnexal torsion: review of the literature. J Minim Invasive Gynecol 2014; 21: 196-202.

27. Hurh PJ, Meyer JS, Shaaban A. Ultrasound of a torsed ovary: characteristic gray-scale appearance despite normal arterial and venous flow on Doppler. Pediatr Radiol 2002; 32: 586-8.

28. Houry D, Abbott JT. Ovarian torsion: a fifteen-year review. Ann Emerg Med 2001; 38: 156-9.

29. Raicevic M, Saxena AK. Review of laparoscopic management of mature cystic teratoma of ovaries in children. J Indian Assoc Pediatr Surg 2019; 24: 92-6.

30. Rossi BV, Ference EH, Zurakowski D, et al. The clinical presentation and surgical management of adnexal torsion in the pediatric and adolescent population. J Pediatr Adolesc Gynecol 2012; 25: 109-13.

31. Oltmann SC, Fischer A, Barber R, et al. Cannot exclude torsion: a 15-year review. J Pediatr Surg 2009; 44: 1212-6.

32. Chang HC, Bhatt S, Dogra VS. Pearls and pitfalls in diagnosis of ovarian torsion. Radiographics 2008; 28: 1355-68. 
33. Yancey LM. Intermittent torsion of a normal ovary in a child associated with use of a trampoline. J Emerg Med 2012; 42: 409-12.

34. Descargues G, Tinlot-Mauger F, Gravier A, et al. Adnexal torsion: a report on forty-five cases. Eur J Obstet Gynecol Reprod Biol 2001; 98: 91-6.

35. Mordehai J, Mares AJ, Barki Y, et al. Torsion of uterine adnexa in neonates and children: a report of 20 cases. J Pediatr Surg 1991; 26: 1195-9.

36. Sommerville M, Grimes DA, Koonings PP, et al. Ovarian neoplasms and the risk of adnexal torsion. Am J Obstet Gynecol 1991; 164: 577-8.

37. Oltmann SC, Fischer A, Barber R, et al. Pediatric ovarian malignancy presenting as ovarian torsion: incidence and relevance. J Pediatr Surg 2010; 45: 135-9.

38. Cribb B, Vishwanath N, Upadhyay V. Paediatric ovarian lesions - the experience at Starship Children's Hospital, New Zealand. N Z Med J 2014; 127: 41-51.

39. Linam LE, Darolia R, Naffaa LN, et al. US findings of adnexal torsion in children and adolescents: size really does matter. Pediatr Radiol 2007; 37: 1013-9.

40. Walker SK, Lal DR, Boyd KP, Sato TT. Management of pediatric ovarian torsion: evidence of follicular development after ovarian preservation. Surgery 2018; 163: 547-52.

41. Ngo AV, Otjen JP, Marguerite T, et al. Pediatric ovarian torsion: a pictorial review. Pediatr Radiol 2015; 45: 1845-55.

42. Akkoyun I, Gulen S. Laparoscopic cystectomy for the treatment of benign ovarian cysts in children: an analysis of 21 cases. J Pediatr Adolesc Gynecol 2012; 25: 364-6.

43. Kilincaslan H, Cipe G, Aydogdu I, et al. Pure laparoscopic management of a giant ovarian cyst in an adolescent. Am J Case Rep 2014; 15: 4-6.

44. Ateş O, Karakaya E, Hakgüder G, et al. Laparoscopic excision of a giant ovarian cyst after ultrasound-guided drainage. J Pediatr Surg 2006; 41: E9-11.

45. Ma KK, Tsui PZ, Wong WC, et al. Laparoscopic management of large ovarian cysts: more than cosmetic considerations. Hong Kong Med J 2004; 10: 139-41.

46. Salem AFH. Laparoscopic excision of large ovarian cysts. J Obstet Gynaecol Res 2002; 28: 290-4

47. Dolan MS, Boulanger SC, Salameh JR. Laparoscopic management of giant ovarian cyst. JSLS 2006; 10: 254-6.

48. Kilincaslan H, Cipe G, Aydogdu I, et al. Pure laparoscopic management of a giant ovarian cyst in an adolescent. Am J Case Rep 2014; 15: 4-6.

49. Eltabbakh GH, Charboneau AM, Eltabbakh NG. Laparoscopic surgery for large benign ovarian cysts. Gynecol Oncol 2008; 108: $72-6$.

50. Coccia ME, Rizzello F, Bracco GL, Scarselli G. Seven-liter ovarian cyst in an adolescent treated by minimal access surgery: laparoscopy and open cystectomy. J Pediatr Surg 2009; 44: E5-8.

51. Cevrioglu AS, Polat C, Fenkci V, et al. Laparoscopic management following ultrasonographic-guided drainage in a patient with giant paraovarian cyst. Surg Endosc 2004; 18: 346.

52. Goh SM, Yam J, Loh F, et al. Minimal access approach to the management of large ovarian cysts. Surg Endosc 2007; 21: 80-3.

53. Patel AG, Parker JE, Wallwork B, et al. Massive splenomegaly is associated with significant morbidity after laparoscopic splenectomy. Ann Surg 2003; 238: 235-40.
54. Meinhold-Heerlein I, Fotopoulou C, Harter P, et al. The new WHO classification of ovarian, fallopian tube, and primary peritoneal cancer and its clinical implications. Arch Gynecol Obstet 2016; 293: 695-700.

55. Parmentier B, Vaz E, Chabaud-Williamson M, et al. Mucinous cystadenoma arising 3 years after ovarian-sparing surgery for mature teratoma in child. J Pediatr Surg 2010; 45: 9-12.

56. Karaman A, Azili MN, Boduroglu EC, et al. A huge ovarian mucinous cystadenoma in a 14-year-old premenarchal girl: review on ovarian mucinous tumor in premenarchal girls. J Pediatr Adolesc Gynecol 2008; 21: 41-4.

57. Sri Paran T, Mortell A, Devaney D, et al. Mucinous cystadenoma of the ovary in perimenarchal girls. Pediatr Surg Int 2006; 22: 224-7.

58. Lack EE, Young RH, Scully RE. Pathology of ovarian neoplasms in childhood and adolescence. Pathol Annu 1992; 27: 281-356.

59. Massicot R, Rousseau V, Ahmed A, et al. Serous and seromucinous infantile ovarian cystadenomas. A study of 42 cases. Eur J Obstet Gynecol Reprod Biol 2009; 142: 64-7.

60. Oltmann SC, Garcia N, Barber R, et al. Can we preoperatively risk stratify ovarian masses for malignancy? J Pediatr Surg 2010; 45: 130-4

61. Zolton J, Maseelall P. Evaluation of ovarian cysts in adolescents. Open J Obstet Gynecol 2013; 3: 12-6.

62. Ozcan R, Kuruoglu S, Dervisoglu S, et al. Ovary-sparing surgery for teratomas in children. Pediatr Surg Int 2013; 29: 233-7.

63. Berger-Chen S, Herzog T, Lewin S, et al. Access to conservative surgical therapy for adolescents with benign ovarian masses. Obstet Gynecol 2012; 119: 270-5.

64. Brookfield K, Cheung M, Koniaris L, et al. A population-based analysis of 1037 malignant ovarian tumors in the pediatric population. J Surg Res 2009; 156: 45-9.

65. Chabaud-Williamson M, Netchine I, Fasola S, et al. Ovariansparing surgery for ovarian teratoma in children. Pediatr Blood Cancer 2011; 57: 429-34.

66. Abbas PI, Dietrich JE, Francis JA, et al. Ovarian-sparing surgery in pediatric benign ovarian tumors. J Pediatr Adolesc Gynecol 2016; 29: 506-10.

67. Oue T, Uehara S, Sasaki T, et al. Treatment and ovarian preservation in children with ovarian tumors. J Pediatr Surg 2015; 50: 2116-8.

68. Reddy J, Laufer MR. Advantage of conservative surgical management of large ovarian neoplasms in adolescents. Fertil Steril 2009; 91: 1941-4.

69. Spinelli C, Di Giacomo M, Mucci N, Massart F. Hemorragic corpus luteum cysts: an unusual problem for pediatric surgeons. J Pediatr Adolesc Gynecol 2009; 22: 163-7.

70. Oltmann SC, Garcia NM, Barber R, et al. Pediatric ovarian malignancies: how efficacious are current staging practices? I Pediatr Surg 2010; 45: 1096-102.

71. Vrijland WW, Jeekel J, van Geldorp HJ, et al. Abdominal adhesions: intestinal obstruction, pain, and infertility. Surg Endosc 2003; 17: 1017-22.

72. Gutt CN, Oniu T, Schemmer P, et al. Fewer adhesions induced by laparoscopic surgery? Surg Endosc 2004; 18: 898-906.

73. Awonuga AO, Saed GM, Diamond MP. Laparoscopy in gynecologic surgery: adhesion development, prevention, and use of adjunctive therapies. Clin Obstet Gynecol 2009; 52: 412-22. 
74. Towne BH, Mahour GH, Woolley MM, Isaacs H Jr. Ovarian cysts and tumors in infancy and childhood. J Pediatr Surg 1975; 10: 311-20.

75. Sharp HT. Laparoscopy in children. Clin Obstet Gynecol 1997; 40: 210-8.

76. Panteli Ch, Minocha A, Kulkarni MS, Tsang T. The role of laparoscopy in the management of adnexal lesions in children. Surg Laparosc Endosc Percutan Tech 2009; 19: 514-7.

Received: 2.03 .2020 , accepted: 5.03 .2020 